\title{
Endoscopic ultrasound and endoscopic submucosal dissection with a multitraction device for a colonic submucosal lesion
}

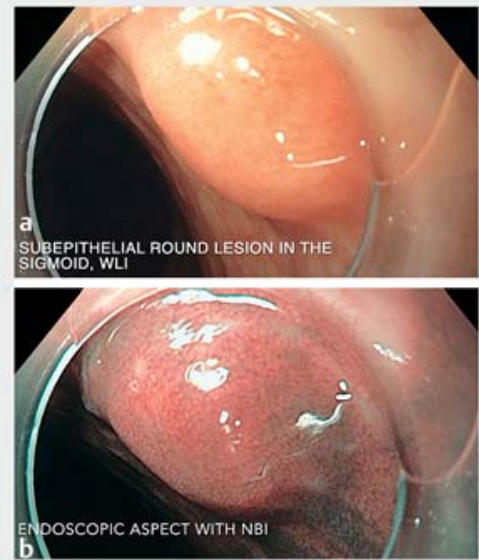

- Fig. 1 Endoscopic images of a subepithelial round lesion in the sigmoid colon seen on: a white-light imaging; b narrowband imaging.

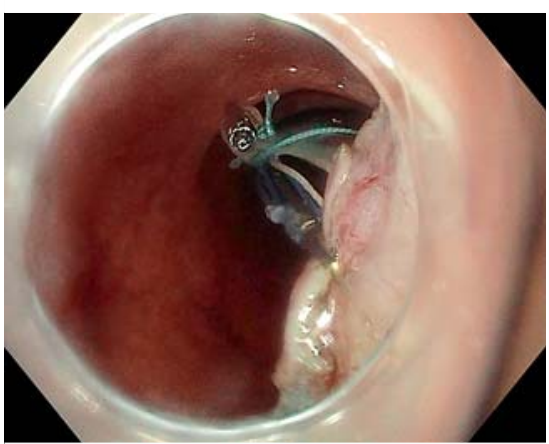

- Fig. 2 Endoscopic view of the multitraction device in position.

With the increasing number of screening colonoscopies performed, better bowel preparation, and advancements in endoscopic image quality, asymptomatic small lesions are detected more frequently. Where there is suspicion of a submucosal neuroendocrine tumor (NET), en bloc resection is advised [1] because complete resection allows for better histopathological characterization and, in low risk cases, no endoscopic follow-up.
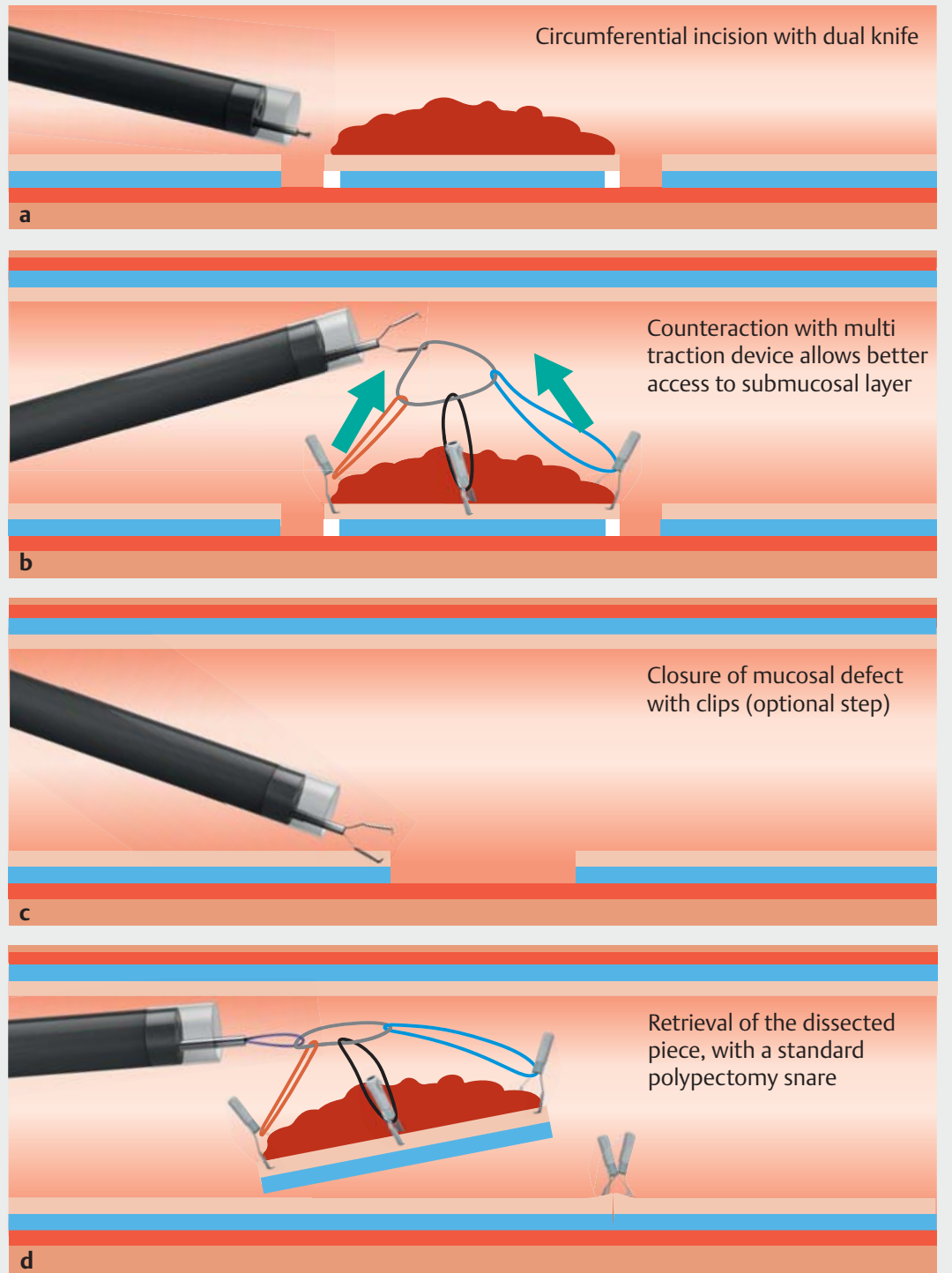

Fig. 3 Schematic showing the steps involved in endoscopic submucosal dissection using the multitraction device.

We report here the case of a 59-year-old man referred to our endoscopy department for a small subepithelial lesion of the sigmoid colon. The differential diagnosis included a lipoma, NET, neurofibroma, or mesenchymal tumor, such as a gastrointestinal stromal tumor (GIST). The mucosa covering the subepithelial lesion was normal on white-light imaging and narrow-band imaging ( $>$ Fig. 1). The initial superficial biopsy showed lymphoid structures with atypia. Endoscopic ultrasound (EUS) was performed. It showed a well-defined, hypoechogenic 7.2-mm lesion located in the submucosa (uT1). There were no suspect lymph 


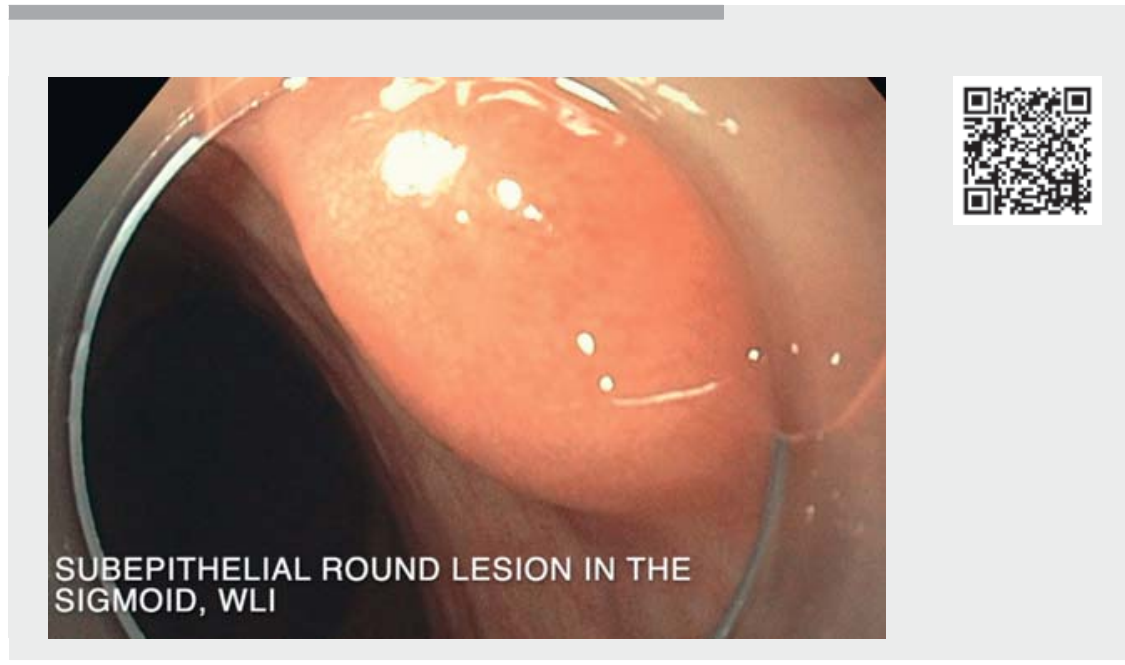

$\checkmark$ Video 1 Endoscopic ultrasound scanning and endoscopic submucosal dissection with a multitraction device are performed for a colonic submucosal lesion that was found on histopathology to be a benign colonic lymph node. nodes located in the nearby area $(\triangleright$ Video 1 ).

We decided to perform a diagnostic en bloc resection by endoscopic submucosal dissection (ESD). After the submucosal injection had been performed, a circumferential incision was made. A multitraction device [2] with two loops was used to better expose the submucosal layer and allow complete resection ( $\triangleright$ Fig. 2 and Fig.3). There were no complications after the procedure. Histology revealed complete resection of an isolated submucosal lymph node, harboring no cancerous cells. No particular follow-up was needed.

To our knowledge, this is the first video case report showing the endoscopic characterization with EUS and ESD of a colonic submucosal benign lymph node. This case illustrates the challenges of differentiating benign from potentially malignant small colonic submucosal lesions, and the advantages of performing en bloc endoscopic resection by ESD with a traction strategy.

Endoscopy_UCTN_Code_TTT_1AQ_2AD

\section{Competing interests}

The authors declare that they have no conflict of interest.

The authors

Lucile Héroin ${ }^{1}$ @ Pierre Lafeuille ${ }^{2}$, Tanguy Fenouil $^{3}$, Mathieu Pioche ${ }^{2}$, Jérôme Rivory ${ }^{2}$, Clara Yzet $^{2}$, Alexandru Lupu ${ }^{2}$

1 Gastroenterology and Hepatology Unit, Hôpitaux Universitaires de Strasbourg, Strasbourg, France

2 Department of Endoscopy and Hepatogastroenterology, Pavillon L, Hôpital Edouard Herriot, Lyon, France

3 Institut de Pathologie Est, Hospices Civils de Lyon, Lyon, France

\section{Corresponding author}

\section{Lucile Héroin, MD}

Gastroenterology and Hepatology Unit, Hôpitaux Universitaires de Strasbourg, 1 quai Louis Pasteur, 67000 Strasbourg, France

lucileheroin@gmail.com
[1] Delle Fave G, O'Toole D, Sundin A et al. ENETS Consensus Guidelines Update for Gastroduodenal Neuroendocrine Neoplasms. Neuroendocrinology 2016; 103 : 119-124

[2] Lambin T, Albouys ], Yzet C et al. Endoscopic submucosal dissection of a lateral spreading tumor involving the appendiceal orifice using a multi-traction device. Endoscopy 2021. doi:10.1055/a-1581-7411

\section{Bibliography}

Endoscopy 2022; 54: E696-E697

DOI 10.1055/a-1756-4285

ISSN 0013-726X

published online 28.2.2022

(c) 2022. Thieme. All rights reserved.

Georg Thieme Verlag KG, Rüdigerstraße 14,

70469 Stuttgart, Germany

\section{ENDOSCOPY E-VIDEOS}

https://eref.thieme.de/e-videos

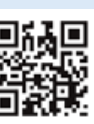

Endoscopy E-Videos is an open access online section, reporting on interesting cases and new techniques in gastroenterological endoscopy. All papers include a high quality video and all contributions are freely accessible online. Processing charges apply (currently EUR 375), discounts and wavers acc. to HINARI are available.

This section has its own submission website at https://mc.manuscriptcentral.com/e-videos 